\title{
The Circumventricular Organs Form a Potential Neural Pathway for Lactate Sensitivity: Implications for Panic Disorder
}

\author{
Anantha Shekhar and Stanley R. Keim \\ Departments of Psychiatry and Pharmacology and Toxicology, Indiana University Medical Center, \\ Indianapolis, Indiana 46202
}

\begin{abstract}
Patients with panic disorder experience panic attacks after intravenous sodium lactate infusions by an as yet unexplained mechanism. Lactate elicits a panic-like response in rats with chronic dysfunction of GABA neurotransmission in the dorsomedial hypothalamus (DMH). The circumventricular organs, organum vasculosum lamina terminalis (OVLT) and subfornical organ (SFO), are potential sites that could detect increases in plasma lactate levels and activate the $\mathrm{DMH}$. To test this, we obtained baseline heart rate $(\mathrm{HR})$ and blood pressure $(\mathrm{BP})$ responses to lactate infusions in rats fit with femoral arterial and venous catheters. Next, unilateral chronic injection cannulae connected to an Alzet infusion pump filled with the GABA synthesis inhibitor L-allylglycine (L-AG) were implanted into the $\mathrm{DMH}$. Another chronic injection cannula was implanted into the region of the OVLT, SFO, or an adjacent control site, the median
\end{abstract}

preoptic area (MePOA). These rats were tested once again with lactate infusions after injection of either artificial cerebrospinal fluid (ACSF) or tetrodotoxin (TTX) into the CVO sites. Injecting TTX into the OVLT completely blocked the lactate-induced response, whereas TTX injections into the SFO or MePOA did not. Also, direct injections of lactate (100 or $500 \mathrm{nl}$ ) into the OVLT elicited robust anxiety-like responses in these rats. These results suggest that the OVLT may be the primary site that detects lactate infusions, activating an anxiety-like response in a compromised $\mathrm{DMH}$, and provide the first neuroanatomical basis for lactate response in panic disorder.

Key words: Alzet pumps; anxiety; dorsomedial hypothalamus; GABA; medial preoptic nucleus; organum vasculosum lamina terminalis; stress; subfornical organ; tetrodotoxin
Panic disorder is a severe anxiety disorder characterized by recurrent panic attacks, i.e., episodes of extreme anxiety accompanied by multiple physiological symptoms of arousal. A majority of patients with panic disorder also experience a panic attack when given intravenous infusions of sodium lactate (Pitts and McClure, 1967; Reiman et al., 1984; Liebowitz et al., 1986). Blocking $\mathrm{GABA}_{\mathrm{A}}$ neurotransmission in the dorsomedial hypothalamus $(\mathrm{DMH})$ of rats elicits a dramatic, panic-like response characterized by increases in heart rate (HR), respiratory rate (RR), blood pressure (BP), and many behavioral measures of anxiety and fear (DiMicco et al., 1992; Shekhar, 1993; Shekhar and Katner; 1995), a response that is blocked by anti-panic treatments (Shekhar, 1994). Furthermore, rats that have a dysfunction of GABA in the DMH show a susceptibility to physiological arousal by lactate infusions similar to patients with panic disorder (Shekhar et al., 1996). Unilateral GABA dysfunction was induced in the DMH of rats by chronically inf using, via Alzet minipumps, L-allylglycine (L-AG), which inhibits glutamic acid decarboxylase (GAD), the synthetic enzyme for GABA (Orlowski et al., 1977). Rats with GABA dysfunction specifically in the $\mathrm{DMH}$ showed significant increases in baseline anxiety and

Received April 11, 1997; revised Sept. 24, 1997; accepted Sept. 29, 1997.

This study was supported by United States Public Health Service Grant MH 52691; the Project Development Program, Research and Sponsored Programs, Indiana University at Indianapolis; and the Association for the Advancement of Mental Health Research and Education, Incorporated. We thank Dr. Lazaros Triarhou for his assistance in histological procedures.

Correspondence should be addressed to Dr. Anantha Shekhar, Institute of Psychiatric Research, Indiana University Medical Center, 791 Union Drive, Indianapolis, IN 46202.

Copyright (C) 1997 Society for Neuroscience $\quad 0270-6474 / 97 / 179726-\$ 05.00 / 0$ developed anxiety-like responses with intravenous lactate infusions (Shekhar et al., 1996).

Understanding the neural pathways by which intravenous lactate infusions interact with a compromised $\mathrm{DMH}$ to elicit a panic-like response in rats, i.e., lactate vulnerability, would be important in understanding the pathophysiology of human panic disorder. The DMH has extensive projections to and from several circumventricular organs (CVOs), areas in the CNS that lack a blood-brain barrier (Ter Horst and Luiten, 1986) and therefore serve as "sensors" of changes in osmolarity, $\mathrm{pH}$, and other plasma parameters (Buggy et al., 1979; Thrasher and Keil, 1987; Richard and Bourque, 1992; Johnson and Gross, 1993; Kovacs and Sawchenko, 1993). These anatomical connections suggest a potential mechanism by which many peripheral plasma parameters can be relayed to the DMH. Among the three major circumventricular organs that receive afferents from the $\mathrm{DMH}$, i.e., the area postrema (AP), subfornical organ (SFO), and organum vasculosum lamina terminalis (OVLT), the OVLT and, to a lesser extent, the SFO have projections back to the DMH (Ter Horst and Luiten, 1986). Thus the OVLT and possibly the SFO could play a critical role in detecting peripheral lactate infusions first and then in activating an already compromised DMH by their efferents, resulting in physiological arousal.

If sensory information about peripheral lactate infusions arising from the CVOs is essential for the DMH-mediated anxiety response, then blocking neural transmission by injecting tetrodotoxin (TTX; Bosker et al., 1994; Corwin et al., 1995) into the OVLT and/or SFO would be predicted to block the lactate response. Similarly, if the CVOs are the major "sensory" organs that relay the lactate stimulus to the $\mathrm{DMH}$, then, in rats with GABA dysfunction in the DMH, injecting a small volume (100- 

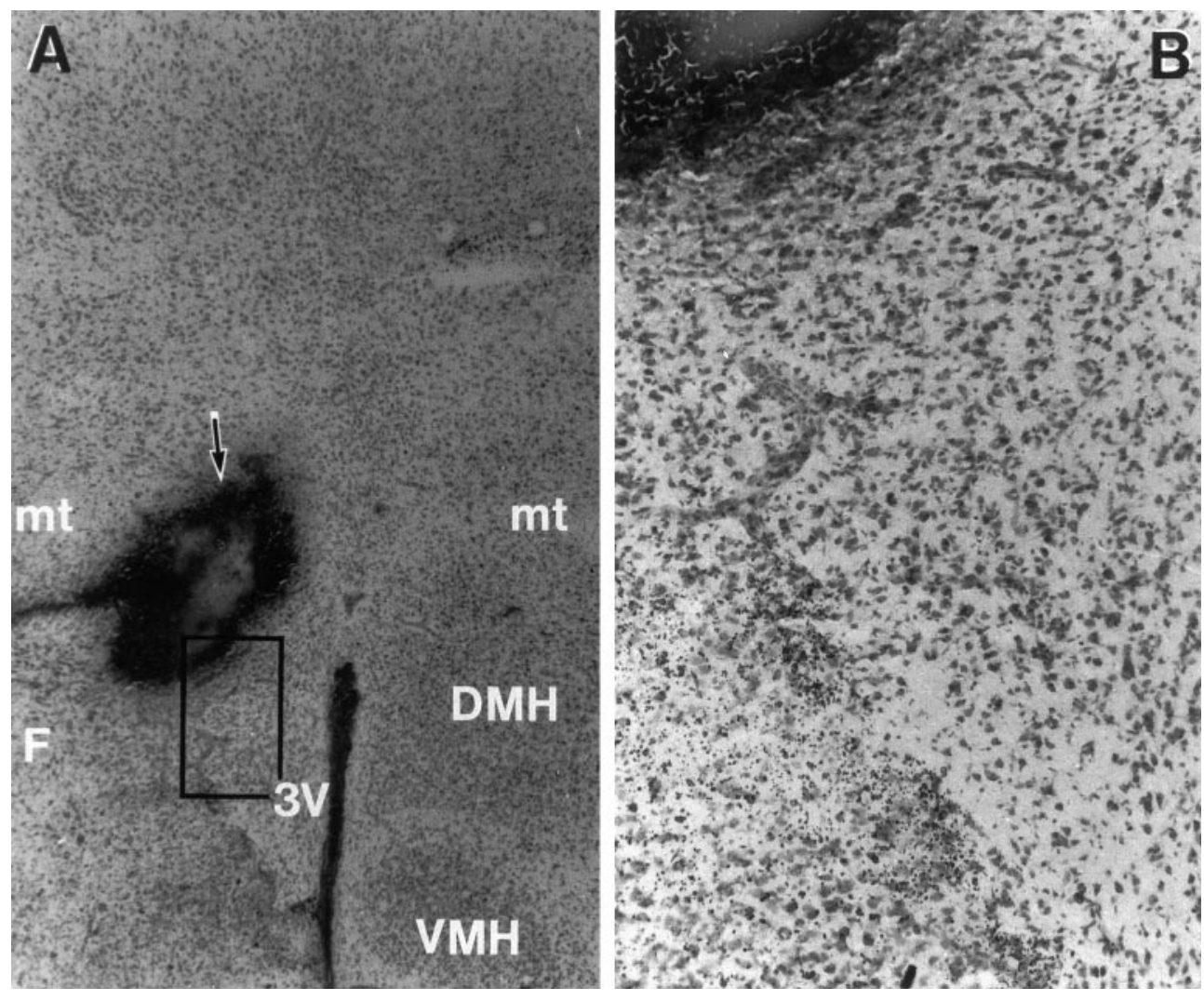

Figure 1. Representative photomicrograph of histological sections (magnification, $8 \times)$ showing $(A)$ the site of Alzet pump cannula implantation (marked by arrow) in the DMH. The sites were marked by injecting $50 \%$ India ink, and only data from the animals with proper cannulae placement were used in the analysis. The injection site is impregnated with India ink, and some tissue necrosis at the site can be seen. However, $B$ shows a higher magnification $(32 \times)$ photomicrograph of the DMH (area marked by the black rectangle in $A$ ) on the side of the cannula implantation, demonstrating that the implantation of the Alzet pumps did not result in the destruction of cells in the majority of the $\mathrm{DMH}$, thereby decreasing GAD activity. Further, the same degree of cannula damage was seen in the DMH of rats implanted with D-AG pumps, suggesting that the possible tissue damage was not causing the lactate response. $D M H$, Dorsomedial hypothalamus; $F$, fornix; $m t$, mamillothalamic tract; $V M H$, ventromedial hypothalamus; $3 \mathrm{~V}$, third ventricle.
$500 \mathrm{nl}$ ) of sodium lactate directly into the CVOs also would be predicted to elicit a panic-like response similar to intravenous lactate infusions. The present study was conducted to test both of these hypotheses.

\section{MATERIALS AND METHODS}

All experiments were conducted on male Sprague Dawley rats (300-350 gm; Harlan Laboratories, Indianapolis, IN) that were housed in individual plastic cages in a temperature-controlled room $\left(72^{\circ} \mathrm{F}\right)$, kept on a $12 \mathrm{hr}$ day-night cycle, and given ad libitum food and water.

Surgical procedures. Rats were implanted first with femoral arterial and venous catheters as previously described (Shekhar, 1993). The next day, after being tested for baseline lactate response, they were implanted with the appropriate Alzet pump in the DMH and the microinjection cannula in the CVO site. Implantation of Alzet minipumps into the DMH also has been described previously (Shekhar et al., 1996). An L-shaped pump cannula with a side arm attached to a small Tygon tube was used for pump implantations. Once the cannula was placed at the coordinates of the $\mathrm{DMH}, 50 \mathrm{pmol} / 100 \mathrm{nl}$ of the $\mathrm{GABA}_{\mathrm{A}}$ receptor antagonist bicuculline methiodide (BMI) was injected through the side tubing to ascertain that the tip was placed at the reactive site (i.e., where BMI elicits $>50$ beats/min increases in $\mathrm{HR}$ ) in the $\mathrm{DMH}$. Once the reactive site was found, the side tubing was connected to the metal connector in the Alzet minipump (model 2002) that was filled previously with the desired infusion fluid. Then the pump was sutured under the skin in the nape of the neck, and the connector and cannula were cemented to the skull as described previously (Shekhar et al., 1996). The concentration of the allylglycine solutions is such that $3.5 \mathrm{nmol} / 0.5 \mathrm{\mu l}$ per hour of the drug was infused into the DMH. Chronic microinjection cannulae were implanted stereotaxically in the region of the OVLT, SFO, and $1 \mathrm{~mm}$ lateral to the OVLT, corresponding to the medial preoptic area (mePOA). The stereotaxic coordinates from bregma for the sites, using a $10^{\circ}$ angle from the vertical plane with the incisor bar set at $+5^{\circ}$ included the following: OVLT, anterior (A) $2.4 \mathrm{~mm}$, lateral (L) $1.0 \mathrm{~mm}$, and ventral (V) $8.5 \mathrm{~mm}$; SFO, A $0.2 \mathrm{~mm}, \mathrm{~L} 1.0 \mathrm{~mm}$, and V $4.5 \mathrm{~mm}$; mePOA, A $2.4 \mathrm{~mm}$, L $2.0 \mathrm{~mm}$, and $\mathrm{V} 8.5 \mathrm{~mm}$.

Social interaction test. The social interaction (SI) test is a fully validated test of experimental anxiety in rats (File, 1980), and the procedure as used in our laboratory has been described previously (Sanders and
Shekhar, 1995; Shekhar and Katner, 1995). The apparatus itself consists of a solid wooden box with an open roof $36 \times 36$ " wide with walls 12 " high. A video camera is fixed above the box, and all behavioral tests are videotaped. The "experimental" rat and an unfamiliar "partner" rat are both placed in the center of the box and allowed to interact freely for a period of $5 \mathrm{~min}$. Then the number of seconds of nonaggressive physical contact (grooming, sniffing, crawling over and under, etc.) initiated by the "experimental" rat is counted. Sessions are scored at a later time by two raters, of whom at least one is blind to any drug treatment.

Measurement of GAD activity. The radiometric assay for GAD (modified from Bostwick and Le, 1991; Shekhar et al., 1996) was based on supplying the enzyme with glutamate (substrate) with a ${ }^{14} \mathrm{C}$-labeled carboxyl group and measuring the liberated ${ }^{14} \mathrm{CO}_{2}$. The tissue was homogenized with $20 \mathrm{vol}$ of a solution containing EDTA (1 mM), Triton $\mathrm{X}-100(0.2 \% \mathrm{v} / \mathrm{v})$, and aminoethanethiol $(1 \mathrm{mM})$ in phosphate buffer, $\mathrm{pH}$ 7. Each well of tissue culture plate (Falcon 3070) received $10 \mu \mathrm{l}$ of tissue homogenate or blank (in triplicates) and $10 \mu \mathrm{l}$ of buffer substrate (glutamate $12.5 \mathrm{~mm}$; pyridoxal phosphate $0.5 \mathrm{~mm}$; and ${ }^{14} \mathrm{C}$-glutamate, $4 \mu \mathrm{Ci}$ in $10 \mathrm{mM} \mathrm{PO}_{4}$ buffer) after which the plate was covered with a $14 \times 11$ $\mathrm{cm}$ sheet of gel blot paper, latched shut, incubated in a $37^{\circ} \mathrm{C}$ water bath for $30 \mathrm{~min}$, and then transferred to a $60^{\circ} \mathrm{C}$ bath for $45 \mathrm{~min}$. The method for measuring the trapped ${ }^{14} \mathrm{CO}_{2}$ has been described previously (Bostwick and Le, 1991).

Experimental procedure. First, rats $(n=24)$ were fit with femoral arterial catheters for recording BP and HR and with venous catheters for intravenous infusions. After recovery, baseline anxiety levels were obtained by using the SI test to measure the change in "anxiety" from baseline state (i.e., before Alzet pump implantation into the $\mathrm{DMH}$ ) to the postpump state. After the baseline SI test, baseline reactivity to intravenous sodium lactate infusions was determined. The lactate infusion procedure has been described previously (Shekhar et al., 1996). Briefly, rats are given intravenous infusions of $0.9 \%$ saline and $0.5 \mathrm{M}$ sodium lactate $(10 \mathrm{ml} / \mathrm{kg}$ over $15 \mathrm{~min})$, similar to clinical lactate inf usions (Leibowitz et al., 1986), in random order with at least 60 min recovery time between infusions. The intravenous infusions are given while the rats are freely mobile in their home cages. Responses to lactate (HR and $\mathrm{BP})$ that are reported are the differences between changes elicited by lactate and saline infusions.

Then the animals were randomly assigned to four groups ( $n=6$ each): (1) rats implanted with unilateral L-AG Alzet minipumps into the DMH 


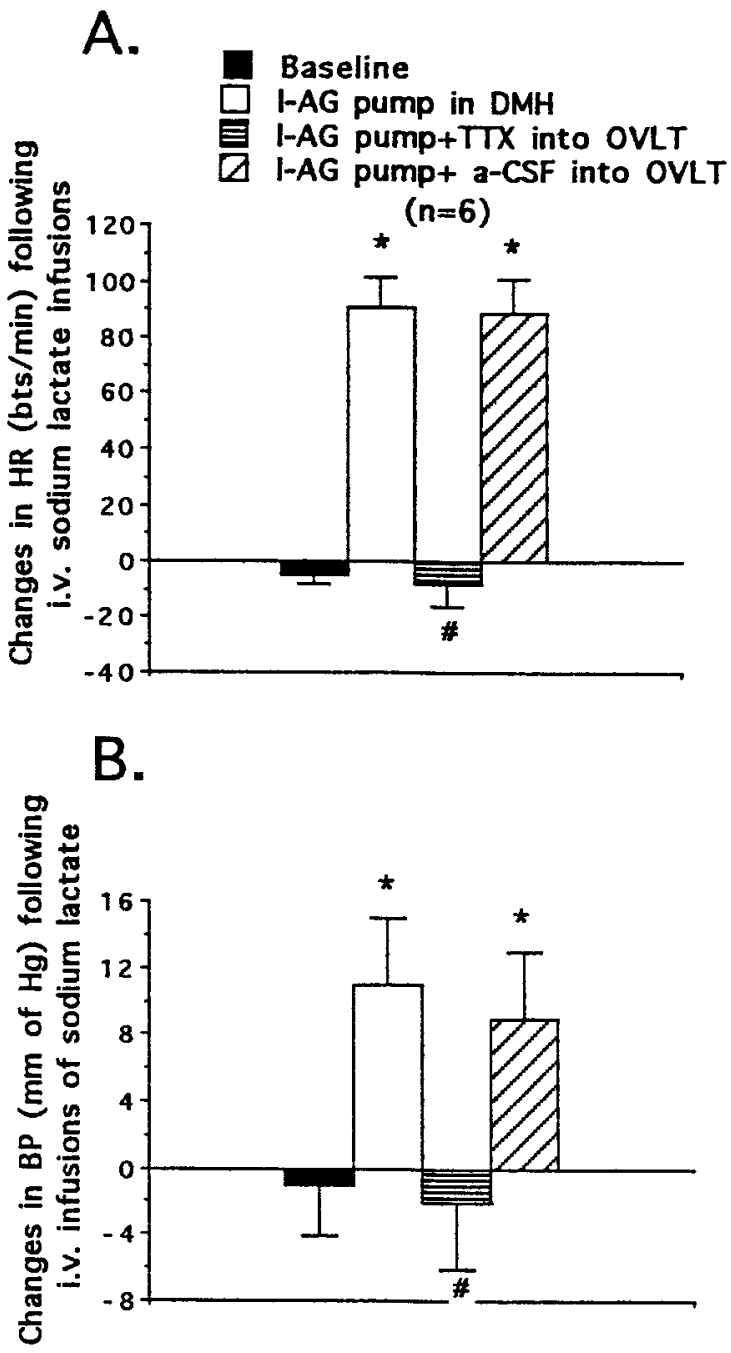

Figure 2. Changes in $(A)$ heart rate $(H R)$ and $(B)$ blood pressure $(B P)$ after intravenous infusions of sodium lactate $(10 \mathrm{ml} / \mathrm{kg}$ of $0.5 \mathrm{~N}$ solution) in rats that were implanted unilaterally with the GABA synthesis inhibitor L-allylglycine-infusing (L-AG) Alzet minipumps into the dorsomedial hypothalamus $(D M H)$. On postpump day 6/7, rats were injected, in random order, either with tetrodotoxin (TTX; 1 pmol in $100 \mathrm{nl}$ ) or with vehicle (ACSF) into the organum vasculosum stria terminalis $(O V L T)$ before intravenous lactate infusions. Data are presented as mean \pm SEM. Symbols show significant difference from baseline $\left(^{*}\right)$ and at $4 \mathrm{~d}(\#)$ after L-AG pump in the DMH; $p<0.05$, repeated measures ANOVA with Fisher's LSD test.

and chronic microinjection cannulae into the OVLT; (2) rats implanted with unilateral D-AG Alzet minipumps into the DMH and chronic microinjection cannulae into the OVLT; (3) rats implanted with unilateral L-AG Alzet minipumps into the DMH and chronic microinjection cannulae into the region lateral to OVLT, i.e., medial preoptic area (mePOA); and (4) rats implanted with unilateral L-AG Alzet minipumps into the DMH and chronic microinjection cannulae into the SFO.

The responses of these rats in the SI test and to lactate infusions were obtained on postpump day 4 , as described previously, to establish that the rats that had L-AG pumps (and not D-AG pumps) had become more anxious and responsive to lactate. On postpump day 5 the animals were injected in random order, both saline vehicle (100 and $500 \mathrm{nl})$ and sodium lactate (100 and $500 \mathrm{nl}$ of $0.5 \mathrm{~N}$ solution) directly into the appropriate CVO site (OVLT, SFO, or mePOA). The rats were injected while they were freely mobile in their home cages and had settled down without significant baseline activity for at least $15 \mathrm{~min}$. There was an interval of at least $30 \mathrm{~min}$ between one injection and the end of the response from the previous injection. The changes in HR, BP, and locomotor activity
Table 1. Effects on implanting Alzet pumps into the DMH, infusing L- or D-allylglycine on the social interaction test

Type of Alzet pump

in the DMH $(n=6$ Site of CVO SI time before SI time $4 \mathrm{~d}$ after each) cannula pump (sec) pump (sec)

L-Allylglycine $\quad$ OVLT $49 \pm 4 \quad 14 \pm 3^{*}$

D-Allylglycine $\quad$ OVLT $\quad 45 \pm 2 \quad 49 \pm 3$

L-Allylglycine mePOA $51 \pm 3 \quad 21 \pm 2^{*}$

L-Allylglycine SFO $49 \pm 3 \quad 24 \pm 3^{*}$

Rats were implanted with Alzet pumps into the DMH, inf using the GABA synthesis inhibitor L-AG or its inactive isomer D-AG; SI time was measured before and $4 \mathrm{~d}$ after pump implantations. These rats also were implanted with their appropriate CVO cannulae for additional injections later. In all groups the rats implanted with L-AG pumps showed significant decreases in SI time by day 4 of pump implantation, indicating an increase in their basal levels of anxiety.

* Significantly different from before pump by repeated measure ANOVA, coupled with Fisher's LSD test; $p<0.05$.

were recorded. The locomotor responses were quantified as the number of crossings and rearings during the first 5 min after lactate injections. Each time the rat crossed the midline of the cage with all four limbs, it was counted as crossing; vertical movement with both front limbs off the ground was counted as a rearing, as previously described (Shekhar and DiMicco, 1987).

On postpump days 6 and 7 one-half of each group was injected first with vehicle (ACSF) into the CVO site; the other one-half was injected with TTX into the CVO site [as tetrodotoxin citrate, $100 \mathrm{nl}$ of $10 \mu \mathrm{M}$ solution, i.e., 1 pmol; doses based on Bosker et al. (1994) and Corwin et al. (1995)]. Approximately 10 min later, animals were given intravenous lactate infusions as previously described, and the HR and BP responses were recorded. Thus, by random selection, one-half of each group $(n=$ 3 ) was given vehicle injection on day 6 and the other one-half was given active drug (TTX) injection into the CVO site on day 6; on day 7 they received the remaining injection for their assigned group.

After day 7 the rats were killed, and their brains were removed and mounted on cryostat at $-20^{\circ} \mathrm{C} ; 40 \mu \mathrm{m}$ sections of the implantation sites were obtained. The sections were stained later with neutral red, and the sites of injection were determined by comparing them with a standard atlas (Paxinos and Watson, 1986). The brain section containing the remaining $\mathrm{DMH}$ was mounted on a frozen platform. The $\mathrm{DMH}$ was microdissected, weighed, and stored in a $-70^{\circ} \mathrm{C}$ freezer until assayed. At a later date, tissue levels of the GABA synthetic enzyme GAD were determined.

Data analysis. All data were expressed as mean \pm SEM. When two or more means of different groups were compared, one-way ANOVA with Fisher's least significant difference (LSD) tests was used. Repeated measures ANOVA was used to test differences between means when repeated measurements were made. Statistical significance was accepted with $p<0.05$.

\section{RESULTS}

Figure 1 shows the photomicrographs of a representative section from a rat with the pump implanted in the DMH (Fig. 1). All 24 animals used in the study were ones with successful implantation in the DMH and the appropriate CVO sites. All of the DMH sites of implantation also were verified physiologically by injecting BMI under anesthesia and obtaining increases in HR and BP. Figure $1 B$ presents the site of pump infusion at a higher magnification, showing that although there is some damage in the $\mathrm{DMH}$ because of pump implantation, particularly in the India ink-impregnated area, the majority of the neurons of the $\mathrm{DMH}$ is still intact surrounding the injection spot marked by India ink. Also, the amount of neuronal damage was similar in the L-AGinfused and the D-AG-infused animals, suggesting that nonspecific injury to the DMH was not causing the lactate response.

Rats that were assigned to L-AG pumps in the DMH and microinjection cannulae in the OVLT were tested at baseline in the SI test and with intravenous lactate infusions. There was no 

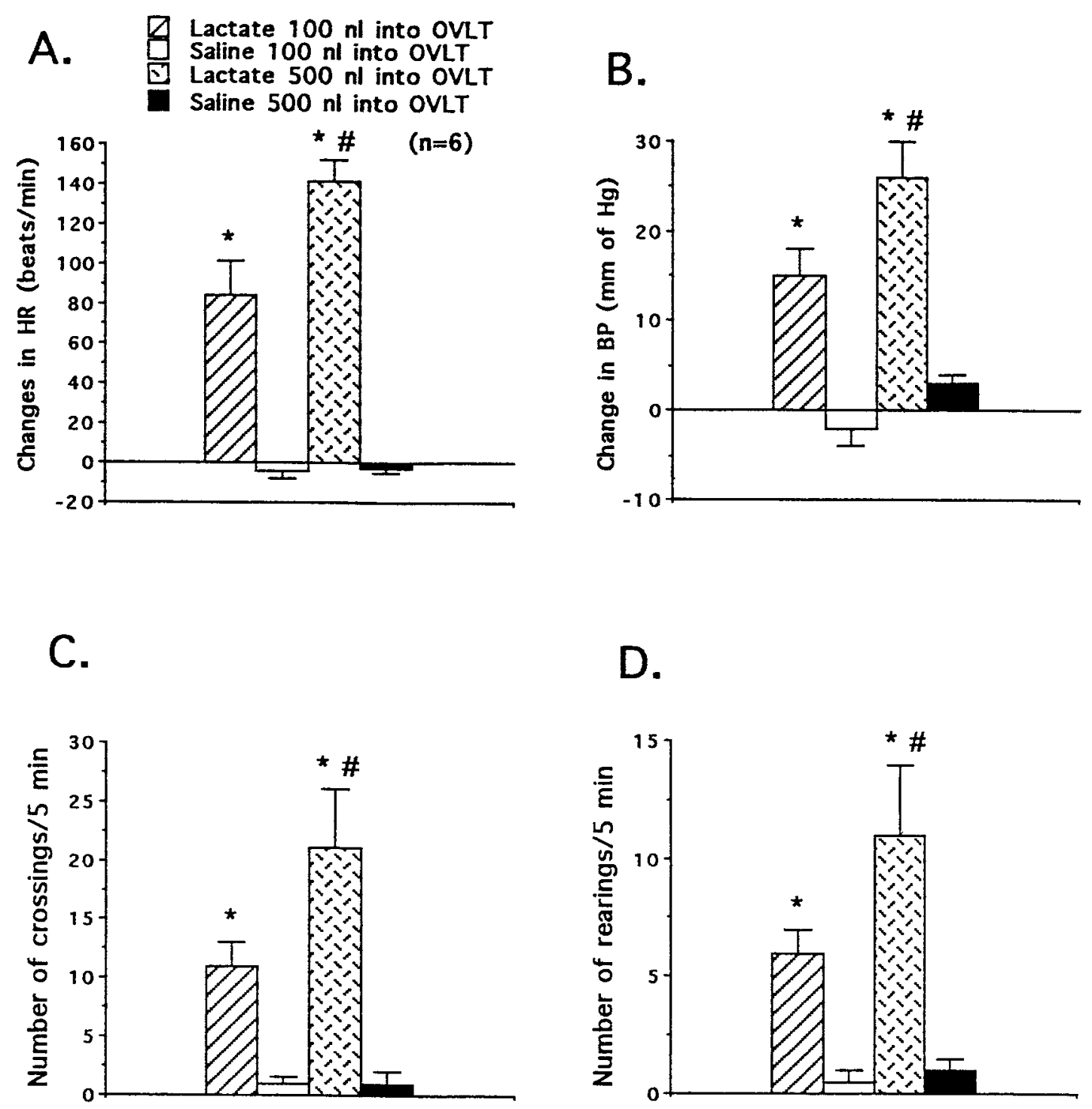

Figure 3. Changes (mean $\pm \mathrm{SEM})$ in $(A)$ heart rate $(H R),(B)$ blood pressure $(B P),(C)$ number of cage crossings, and $(D)$ rearings after direct injections of either sodium lactate $(100$ and $500 \mathrm{nl}$ of $0.5 \mathrm{~N}$ solution) or saline $(100 \mathrm{or} 500 \mathrm{nl})$ into the OVLT of rats that had L-AG Alzet inf usion pumps implanted into the DMH for $5 \mathrm{~d}$. Injection of lactate directly into the OVLT elicited a robust panic-like response. Symbols show significant difference from saline control $\left(^{*}\right)$ and $100 \mathrm{nl}$ of lactate $(\#)$ by repeated measures ANOVA with Fisher's LSD; $p<0.05$.

\begin{tabular}{|c|c|c|c|}
\hline $\begin{array}{l}\text { Type of Alzet pump } \\
\text { in the DMH }(n=6 \\
\text { each) }\end{array}$ & $\begin{array}{l}\text { Site of } \\
\text { CVO cannula }\end{array}$ & $\begin{array}{l}\text { GAD activity on the nonpump } \\
\text { side ( } \mathrm{pmol} / \mathrm{mg} \text { of protein per } \\
30 \mathrm{~min})\end{array}$ & $\begin{array}{l}\text { GAD activity on the pump } \\
\text { side (pmol/mg of protein } \\
\text { per } 30 \mathrm{~min})\end{array}$ \\
\hline L-Allylglycine & OVLT & $1216 \pm 151$ & $704 \pm 40^{*}$ \\
\hline D-Allylglycine & OVLT & $1060 \pm 71$ & $1046 \pm 77$ \\
\hline L-Allylglycine & mePOA & $1346 \pm 97$ & $728 \pm 75^{*}$ \\
\hline L-Allylglycine & SFO & $1139 \pm 194$ & $671 \pm 82^{*}$ \\
\hline
\end{tabular}

Rats were implanted with Alzet pumps into the DMH, infusing the GABA synthesis inhibitor L-AG or its inactive isomer D-AG; GAD activity was measured after completion of all experiments on day 7 of pump implantation. These rats also were implanted with their appropriate CVO cannulae for additional injections later. In all groups the rats implanted with $\mathrm{L}-\mathrm{AG}$ pumps showed significant decreases in GAD activity within the DMH on the side of pump implantation.

*Significantly different from before pump by repeated measure ANOVA, coupled with Fisher's LSD test; $p<0.05$. 
significant physiological arousal with lactate infusions before pump implantation (Fig. $2 A, B$, baseline). They were placed in the SI test again on postpump day 4 to determine changes in their anxiety level. As predicted, L-AG pumps in the DMH elicited a significant decrease in SI time in these rats, indicating that they were more anxious (Table $1 ; F_{(1,10)}=44.5 ; p<0.0001$ ). On postpump day 4 these animals also had become reactive to intravenous lactate infusions, with significant increases in $\mathrm{HR}$ and BP (Fig. 2A,B, day 4). Injection of TTX or vehicle into the OVLT, followed by infusion with intravenous sodium lactate in these rats, revealed that TTX and not ACSF completely blocked the response to lactate infusions (Fig. $2 A, B$ ). When saline or sodium lactate was injected directly into the OVLT of these rats on postpump day 5 , they showed lactate volume-dependent increases in $\mathrm{HR}, \mathrm{BP}$ (Fig. 3A,B), and locomotor activity quantified as crossings and rearings (Fig. 3C,D) when compared with saline injections. Measuring GAD activity in the DMH at the end of the experiment revealed that these animals did, indeed, have significant decreases in GAD activity on the pump side as compared with the nonpump side (Table $2 ; F_{(1,10)}=10.8 ; p=0.008$ ). Figure 4 is a representative histological section showing the site of injection in the OVLT. Thus, in this group with unilateral GABA dysfunction in the DMH, blocking neuronal activity in the OVLT with TTX abolished the lactate response, whereas direct injections of lactate into the OVLT elicited robust physiological and behavioral responses.

In contrast, rats that had D-AG pumps in the $\mathrm{DMH}$ and microinjection cannulae in the OVLT did not show a significant decrease in SI time (Table $1, F_{(1,10)}=0.7 ; p=0.42$ ) or physiological reactivity to lactate infusions on postpump day 4 as compared with baseline (Table 3). Direct injection of lactate into the OVLT in these rats also failed to elicit any physiological or behavioral responses (Table 4). Because there was no significant lactate response, these animals were not injected with TTX into the OVLT. When GAD activity in the DMH was measured in these animals, there were no significant differences in the pump versus nonpump (Table 2) sides, indicating that D-AG is indeed an inactive isomer.

Rats that were assigned to L-AG pumps in the DMH and microinjection cannulae $1 \mathrm{~mm}$ lateral to the OVLT, i.e., mePOA, showed a significant decrease in SI time on postpump day 4 as compared with baseline (Table $1 ; F_{(1,10)}=73.7 ; p=0.0001$ ). On postpump day 4 these animals also had become reactive to intravenous lactate infusions, with significant increases in $\mathrm{HR}$ and $\mathrm{BP}$ (Table 3). Injection of TTX or vehicle into the mePOA, followed by infusion of intravenous sodium lactate in these rats, revealed that TTX not only failed to block the HR and BP responses to lactate infusions but in fact significantly increased the HR responses (Table 3). When saline or sodium lactate was injected directly into the mePOA of these rats on postpump day 5, they showed no significant increases in $\mathrm{HR}, \mathrm{BP}$, and locomotor activity (Table 4). Measuring GAD activity in the DMH revealed that these animals also had significant decreases in GAD activity on the pump side as compared with the nonpump side (Table 2; $\left.F_{(1,10)}=25.4 ; p=0.0005\right)$. A photomicrograph of the histological section confirming the site of injection in the region of the mePOA is shown in Figure 5. Thus, in this group with unilateral GABA dysfunction in the DMH, blocking neuronal activity in the mePOA with TTX enhanced the lactate response, whereas direct injections of lactate into the mePOA elicited no physiological or behavioral responses.

Finally, rats that had L-AG pumps in the DMH and microin-

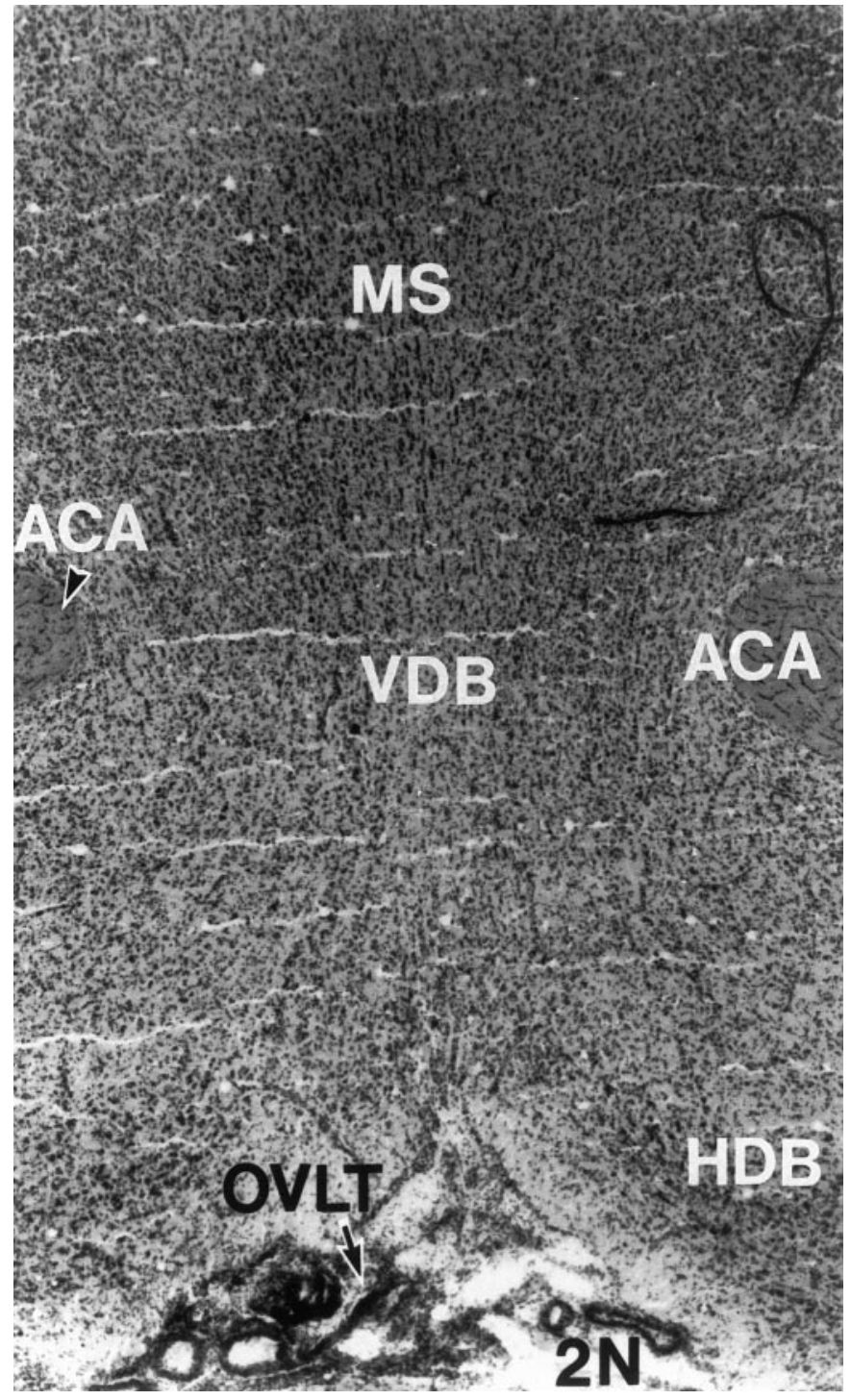

Figure 4. Representative photomicrograph of histological sections (magnification, $8 \times)$ showing the site of microinjection cannula implantation (marked by arrow) in the OVLT. The sites were marked by injecting 100 $\mathrm{nl}$ of $50 \%$ India ink. $A C A$, Anterior commissure, anterior; $H D B$, horizontal limb of the diagonal band; $M S$, medial septal nucleus; $O V L T$, organum vasculosum lamina terminalis; $V D B$, vertical limb of the diagonal band; $2 N$, optic nerve.

jection cannulae in the SFO also showed a significant decrease in SI time (Table $1 ; F_{(1,10)}=41.8 ; p=0.0001$ ) and physiological reactivity to intravenous lactate on postpump day 4 as compared with baseline (Table 3). Injection of TTX into the SFO, followed by infusion of intravenous sodium lactate in these rats, failed to block the HR and BP responses to lactate infusions (Table 3). When sodium lactate was injected directly into the SFO of these rats on postpump day 5, they also showed significant increases in HR, BP, and locomotor activity (Fig. 6) but were less robust than those elicited in the OVLT. Measuring GAD activity in the $\mathrm{DMH}$ revealed that these animals also had significant decreases in GAD activity on the pump side as compared with the nonpump side (Table $2 ; F_{(1,10)}=4.99 ; p=0.05$ ). Figure 7 shows a representative histological verification of the site of injection in the SFO. Thus, in rats with unilateral GABA dysfunction in the DMH, blocking neuronal activity in the SFO with TTX failed to 


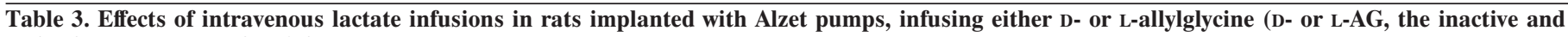
active isomers, respectively) into the DMH

\begin{tabular}{|c|c|c|c|c|}
\hline Pump type in the DMH & $\begin{array}{l}\text { Day of intravenous } \\
\text { lactate infusions }\end{array}$ & $\begin{array}{l}\text { Site and type of mi- } \\
\text { croinjection before } \\
\text { lactate inf usions }\end{array}$ & $\begin{array}{l}\text { Changes in HR after } \\
\text { lactate infusion } \\
\text { (beats/min) }\end{array}$ & $\begin{array}{l}\text { Changes in BP after } \\
\text { lactate infusion } \\
(\mathrm{mm} \text { of } \mathrm{Hg})\end{array}$ \\
\hline \multirow{2}{*}{$\begin{array}{l}\text { D-Allylglycine } \\
\qquad(n=6)\end{array}$} & Baseline (before pump) & None & $-4 \pm 6$ & $-2 \pm 4$ \\
\hline & Day 4 after pump & None & $-3 \pm 4$ & $1 \pm 5$ \\
\hline \multirow{4}{*}{$\begin{array}{l}\text { L-Allylglycine } \\
\quad(n=6)\end{array}$} & Baseline & None & $-7 \pm 3$ & $3 \pm 3$ \\
\hline & Day 4 after pump & None & $104 \pm 6^{*}$ & $18 \pm 4^{*}$ \\
\hline & Days 6/7 after pump & $\mathrm{SFO} ; \mathrm{a}-\mathrm{CSF}$ & $90 \pm 4^{*}$ & $17 \pm 2 *$ \\
\hline & Days 6/7 after pump & SFO; TTX & $124 \pm 22 *$ & $28 \pm 4^{*} \#$ \\
\hline \multirow{4}{*}{$\begin{array}{l}\text { L-Allylglycine } \\
\quad(n=6)\end{array}$} & Baseline & None & $-5 \pm 9$ & $4 \pm 3$ \\
\hline & Day 4 after pump & None & $75 \pm 8^{*}$ & $17 \pm 4^{*}$ \\
\hline & Days 6/7 after pump & mePOA; a-CSF & $70 \pm 4^{*}$ & $14 \pm 2 *$ \\
\hline & Days 6/7 after pump & mePOA; TTX & $122 \pm 9^{*} \#$ & $20 \pm 5^{*}$ \\
\hline
\end{tabular}

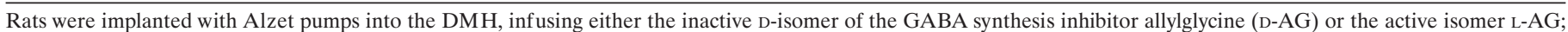

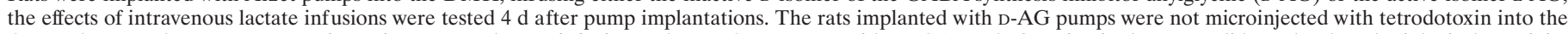

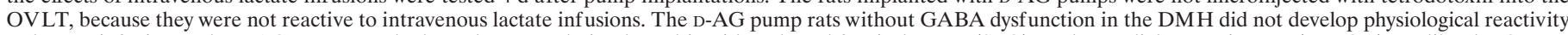

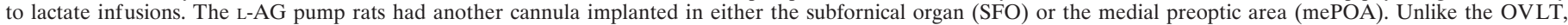
injection of tetrodotoxin into these sites did not block the response elicited by intravenous sodium lactate inf usions.

\begin{tabular}{|c|c|c|c|c|c|c|}
\hline $\begin{array}{l}\text { Type of pump in } \\
\text { the DMH }\end{array}$ & $\begin{array}{l}\text { Site of micro- } \\
\text { injection }\end{array}$ & $\begin{array}{l}\text { Solution mi- } \\
\text { croinjected }\end{array}$ & $\begin{array}{l}\text { Changes in HR } \\
\text { (beats/min) }\end{array}$ & $\begin{array}{l}\text { Changes in BP } \\
(\mathrm{mm} \text { of } \mathrm{Hg})\end{array}$ & $\begin{array}{l}\text { Number of } \\
\text { crossings } / 5 \mathrm{~min}\end{array}$ & $\begin{array}{l}\text { Number of } \\
\text { rearings } / 5 \mathrm{~min}\end{array}$ \\
\hline \multirow{4}{*}{$\begin{array}{l}\text { D-Allylglycine } \\
\quad(n=6)\end{array}$} & \multirow[t]{4}{*}{ OVLT } & Saline $100 \mathrm{nl}$ & $2 \pm 2$ & $-1 \pm 3$ & $0 \pm 1$ & $0 \pm 1$ \\
\hline & & Lactate $100 \mathrm{nl}$ & $-3 \pm 3$ & $2 \pm 2$ & $1 \pm 1$ & $0 \pm 0$ \\
\hline & & Saline $500 \mathrm{nl}$ & $6 \pm 2$ & $4 \pm 3$ & $0 \pm 0$ & $0 \pm 0$ \\
\hline & & Lactate $500 \mathrm{nl}$ & $3 \pm 1$ & $3 \pm 2$ & $0 \pm 1$ & $1 \pm 1$ \\
\hline \multirow{4}{*}{$\begin{array}{l}\text { L-Allylglycine } \\
\qquad(n=6)\end{array}$} & \multirow[t]{4}{*}{ mePOA } & Saline $100 \mathrm{nl}$ & $4 \pm 1$ & $4 \pm 2$ & $0 \pm 1$ & $0 \pm 0$ \\
\hline & & Lactate $100 \mathrm{nl}$ & $4 \pm 4$ & $3 \pm 1$ & $0 \pm 1$ & $0 \pm 0$ \\
\hline & & Saline $500 \mathrm{nl}$ & $2 \pm 3$ & $4 \pm 1$ & $0 \pm 0$ & $1 \pm 1$ \\
\hline & & Lactate $500 \mathrm{nl}$ & $3 \pm 3$ & $6 \pm 2$ & $1 \pm 1$ & $0 \pm 1$ \\
\hline
\end{tabular}

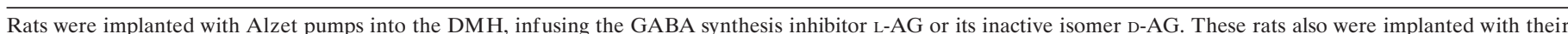

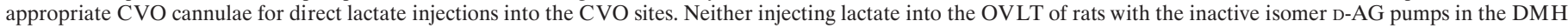
nor injecting lactate into the mePOA of rats with the active L-AG pump in the DMH elicited a panic-like response.

block the lactate response, whereas direct injections of lactate into the SFO elicited physiological or behavioral responses.

\section{DISCUSSION}

The above and previous findings suggest that the DMH may be a critical site in rats that is capable of generating a full panic-like anxiety response. This anxiety circuit appears to be normal under tonic GABAergic inhibition; removing this inhibition elicits sudden, dramatic increases in physiological measures of heart rate, respiratory rate, blood pressure (DiMicco and Abshire, 1987; DiMicco et al., 1992), plasma catecholamine (Wible et al., 1989), corticosterone levels (Keim and Shekhar, 1996), "flight" behavior (Shekhar and DiMicco, 1987), and selective enhancement of "fear" responses (Shekhar et al., 1987) plus an increase in experimental anxiety as measured in a variety of behavioral tests (Shekhar et al., 1990; Shekhar, 1993; Shekhar and Katner, 1995). This response can be blocked by imipramine and clonazepam, two of the effective treatments for human panic disorder (Shekhar, 1994). It should be noted that acute disruption of GABA inhibition in the DMH does not mimic human panic attacks precisely, because increases in plasma catecholamines and corticosterone are not seen consistently during human panic attacks. However, chronic dysfunction in the DMH results in the development of lactate sensitivity similar to patients with panic disor- der (Shekhar et al., 1996). The present study was conducted to clarify some of the potential pathways for the development of the lactate-induced anxiety response in rats with DMH GABA dysfunction.

The above results clearly show that blocking neuronal activity in the OVLT with TTX completely blocks the lactate response in rats with a compromised DMH, indicating that the OVLT indeed may be the primary site that conveys the peripheral lactate stimulus to the DMH (see Fig. 2). This stimulus in turn elicits a full physiological and behavioral response only when DMH function is compromised, as in rats infused with L-AG, a GABA synthesis inhibitor. In rats infused with D-AG, the inactive isomer, there was no decrease in the DMH GAD activity, and when the DMH was thus normal, there were no physiological/behavioral responses to either intravenous lactate infusions (Table 3 ) or direct lactate injections into the OVLT (Table 4). Therefore, a combination of a compromised central panicogenic site, such as the $\mathrm{DMH}$, and the excitatory input from the CVOs, such as the OVLT, appears to be necessary for lactate-induced responses.

In the current study the only test of "anxiety" used is the SI test. Previous studies have shown that infusion of L-AG into the $\mathrm{DMH}$ of rats causes anxiety-like responses in the SI as well as in the elevated plus-maze tests (Shekhar et al., 1996). However, 


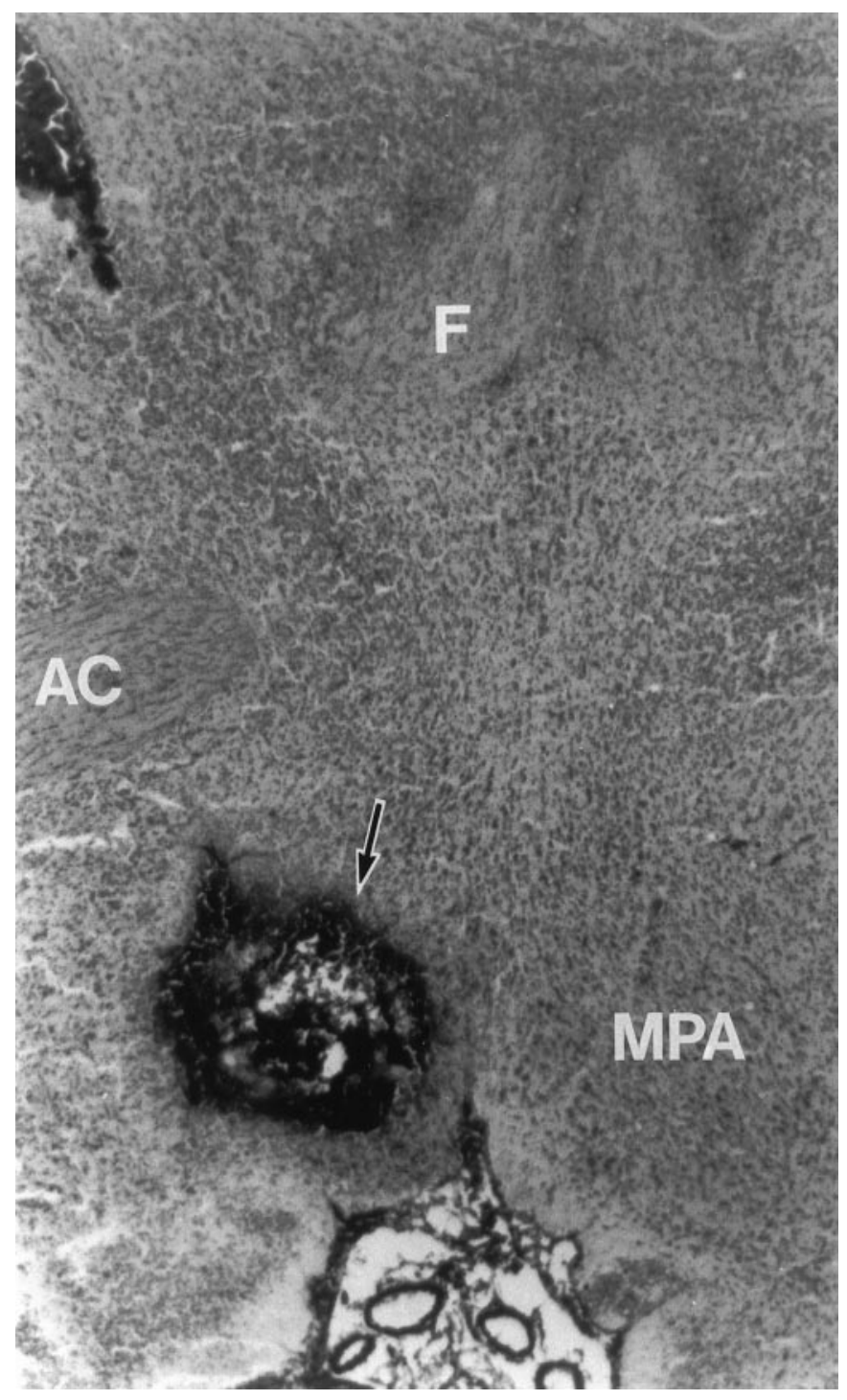

Figure 5. Photomicrograph of a histological section (magnification, $8 \times$ ) showing the site of microinjection cannula implantation (marked by arrow) in the mePOA. The sites were marked by injecting $100 \mathrm{nl}$ of $50 \%$ India ink. $A C$, Anterior commissure; $F$, fornix; $M P A$, medial preoptic area.

because there is considerable variance in the effects of experimental interventions on the response of rats in different tests of anxiety, the limitations of using only one test of anxiety need to be noted.

There is also significant controversy as to the meaning of the lactate sensitivity seen in patients with panic disorder. There is some conflicting evidence about whether peripheral lactate infusions even cross into the CNS. Although some studies have noted that peripherally infused lactate does enter the brain in rodents (Dager et al., 1992) and humans (Dager et al., 1994), others have suggested that it does not (Coplan et al., 1992). As proposed in the present study, if peripheral lactate acts via the CVOs that lack a blood-brain barrier, then the CNS penetration of lactate becomes immaterial. Although lactate infusions clearly cause panic attacks in panic patients, it is possible that these patients simply have a heightened physiological arousal and are likely to respond with a panic attack to a variety of physiological stimuli. This is, in fact, the case because panic patients are sensitive to many "panicogenic" agents such as yohimbine, caffeine, cholecystokinin, $\mathrm{CO}_{2}$, etc. If GABA dysf unction in the DMH of rats does mimic panic disorder, then these rats also would be sensitive to some of the other panicogenic agents in addition to lactate. In a preliminary study of a group of rats with $\mathrm{L}-\mathrm{AG}$ pumps in the DMH that were tested with both intravenous lactate and yohimbine infusions, there were similar physiological and anxiogenic responses to both agents, suggesting that this indeed may be the case (Table 5).

The connections of the CVOs, the $\mathrm{DMH}$, and its projections involved in the lactate response are summarized in Figure 8. The OVLT has strong connections with the DMH (Ter Horst and Luiten, 1986). Under normal conditions the excitatory input from the OVLT, which may involve angiotensin pathways (A. Shekhar and S. Keim, unpublished observations), is unable to elicit the DMH-mediated response because of the presence of a tonic GABAergic inhibition in the DMH. When this normal inhibitory tone in the DMH is compromised, stimulation of the OVLT by lactate infusions in turn would activate the physiological and behavioral responses via the DMH. The SFO, another CVO in the anterior third ventricle close to the $\mathrm{DMH}$, also may activate a similar response but appears to use the OVLT as an intermediate relay center via its reciprocal connections (Johnson and Gross, 1993), because in rats that had TTX injected into the OVLT, an intact SFO alone was unable to elicit the response to intravenous lactate infusions (Fig. 8). Injection of TTX into the mePOA not only was unable to block but in fact enhanced some of the responses (such as HR) elicited by systemic lactate infusions (Table 3). The mePOA has connections with both the OVLT and SFO as well as with the DMH (Saper and Levisohn, 1983), and the overall effect of blocking the mePOA appears to be a net loss of inhibition on the DMH response. Once activated, the $\mathrm{DMH}$ has efferent projections to a number of areas that regulate emotional and physiological responses, including the following: the PVN (Ter Horst and Luiten, 1986), a major site for endocrine and autonomic outputs (Swanson, 1987); the lateral hypothalamus (Ter Horst and Luiten, 1986), a relay center for autonomic responses associated with emotional reactions (LeDoux et al., 1988); bed nucleus of stria terminalis, hippocampus, and frontal cortex (Swanson, 1987), regions known to be associated with emotions and learning; periaqueductal gray at the level of cranial nerve III (Watson et al., 1982; Ter Horst and Luiten, 1986), another site involved in physiological and behavioral effects of emotional responses; nucleus tractus solitarius, site of sensory information from peripheral autonomic structures; pressor area of the ventrolateral medulla, site that regulates the sympathetic tone; nucleus ambiguus and dorsal motor nucleus of the vagus, major parasympathetic output areas (Ter Horst and Luiten, 1986); and the intermediolateral column of the spinal cord, site of the preganglionic sympathetic neurons (Saper et al., 1976). Therefore, the connections of the $\mathrm{DMH}$ are such that it is able to be a coordinated output center of stress responses (Fig. 8). Indeed, the DMH has been described as a major integrator of emotional and autonomic responses (Bernardis and Bellinger, 1987; DiMicco et al., 1992).

The pathways between the CVOs and the hypothalamus are essential for many homeostatic regulatory mechanisms. In fact, it is suggested that the development of these interoceptor pathways may have been critical in the evolution of biological species that, by their interoceptor role, are thought to be capable of generating powerful emotional and behavioral drives (Denton et al., 1996). Activation of such pathways in the absence of normal regulatory mechanisms conceivably could lead to a panic-like response, an 

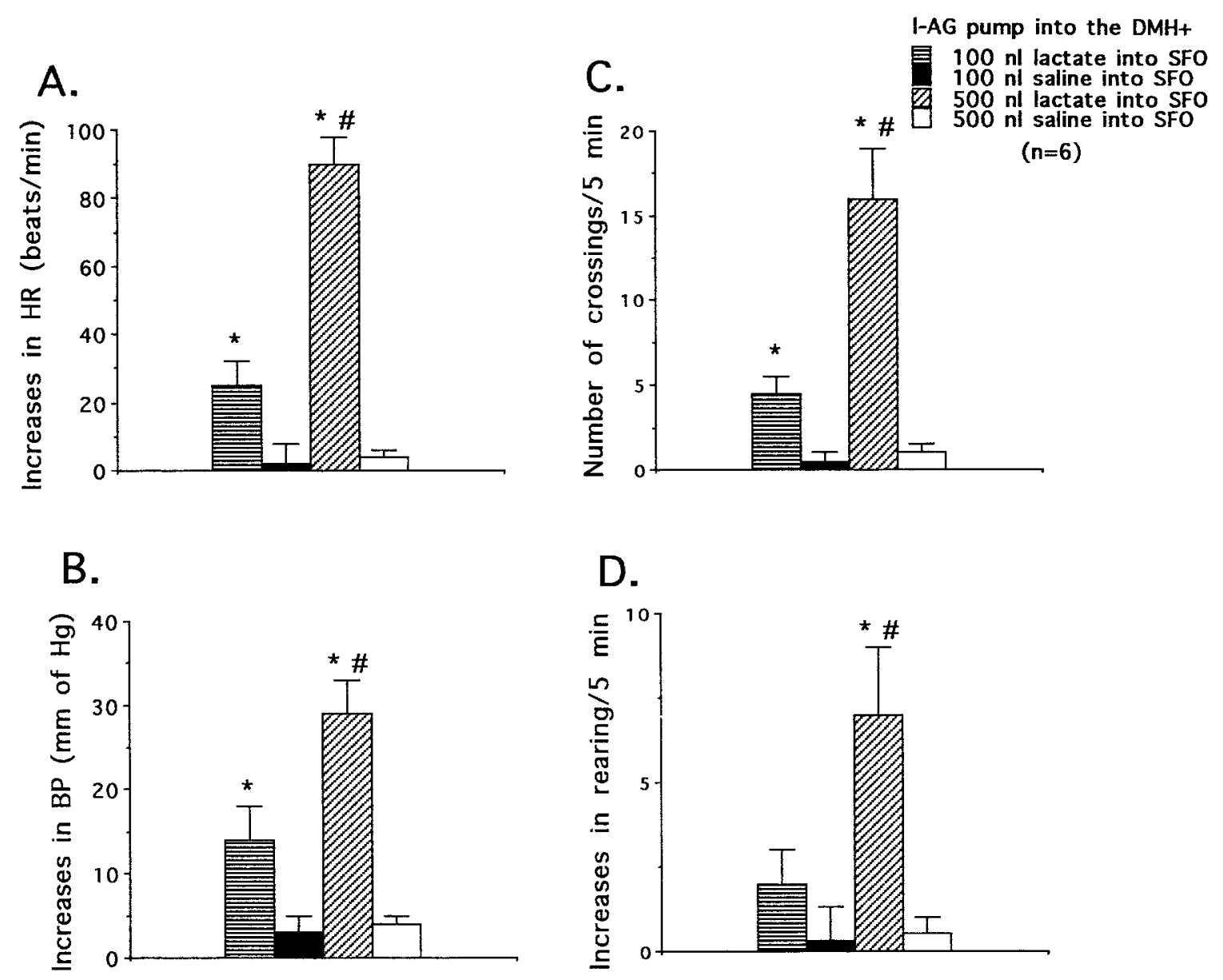

Figure 6. Changes (mean $\pm \mathrm{SEM})$ in $(A)$ heart rate $(H R),(B)$ blood pressure $(B P),(C)$ number of cage crossings, and $(D)$ rearings after direct injections of either sodium lactate (100 and $500 \mathrm{nl}$ of $0.5 \mathrm{~N}$ solution) or saline $(100 \mathrm{or} 500 \mathrm{nl})$ into the SFO of rats that had L-AG Alzet infusion pumps implanted into the DMH for $5 \mathrm{~d}$. Direct injection of lactate into the SFO in these rats also elicited a panic-like response that was less robust than the response elicited by injecting lactate into the OVLT. Symbols show significant difference from saline control $(*)$ and $100 \mathrm{nl}$ of lactate $(\#)$ by repeated measures ANOVA with Fisher's LSD; $p<0.05$.

essential survival reflex. In addition to the DMH, there are other CNS regions capable of eliciting physiological and behavioral responses when the local GABAergic inhibition is removed, such as the basolateral amygdala (Sanders and Shekhar, 1991, 1995) and the midbrain central gray (DiScala et al., 1984). These structures also have close connections with the CVOs (Johnson and Gross, 1993) and may be capable of becoming neural substrates for abnormal panic-like responses when their function is compromised. For example, the basolateral amygdala appears to develop a form of long-term sensitization after repeated GABA blockade, leading to chronic high levels of anxiety in rats (Sanders et al., 1995). Preliminary studies indicate that these sensitized rats also may become responsive to lactate infusions (T. Sajdyk and A. Shekhar, unpublished observations). The SFO has extensive connections with the amygdala (Johnson and Gross, 1993) and may be an important site in eliciting the lactate response in the amygdala-primed rats (A. Shekhar and S. Keim, unpublished observations). Thus a variety of forebrain and brainstem structures that are substrates for the anxiety responses may become the pathological sites in the development of panic disorders.

The involvement of the CVOs in the lactate-induced panic response also may explain why patients with panic disorder are susceptible to induction of panic response by systemic adminis- trations of a variety of agents like $\mathrm{CO}_{2}$, caffeine, cholecystokinin, norepinephrine, and others (Price et al., 1995). Many of these agents, like lactate, cholecystokinin, and norepinephrine, do not cross the blood-brain barrier easily. However, the CVOs, which lack a blood-brain barrier, can be exposed easily to these circulating substances and in turn stimulate the compromised panicgenerating site (such as the DMH or amygdala), thereby eliciting a response. Such a mechanism also could present a single unifying explanation for the existence of multiple, apparently unrelated agents that seem to induce a panic attack in patients suffering from panic disorder.

In summary, this report presents evidence supporting a specific circuit involving a compromised $\mathrm{DMH}$ and the anterior third ventricular circumventricular organs, OVLT and SFO, which are capable of eliciting an anxiety response after intravenous lactate inf usions. We believe this to be the first description of a putative neuroanatomical pathway for the lactate sensitivity in patients with panic disorder, a phenomenon that has been known for three decades (Pitts and McClure, 1967). In addition, this may provide a starting point for a more detailed delineation of the neural circuitry involved in such responses and the development of panic disorders. 
$\leftarrow$

Figure 7. Photomicrograph of a histological section (magnification, $8 \times$ ) showing the site of microinjection cannula implantation (marked by arrow) in the SFO. The sites were marked by injecting $100 \mathrm{nl}$ of $50 \%$ India ink. $c c$, Corpus callosum; $P T$, paratenial thalamic nucleus; $P V A$, paraventricular thalamic nucleus, anterior; $S F O$, subfornical organ; Sm, stria medullaris thalami; $V H C$, ventral hippocampal commissure.

Table 5. Effects of different intravenous infusions in rats implanted with Alzet pumps, infusing L-allylglycine (L-AG, the GABA synthesis inhibitor) into the DMH

\begin{tabular}{lccl}
$\begin{array}{l}\text { Intravenous } \\
\text { infusion type }\end{array}$ & $\begin{array}{l}\mathrm{HR} \\
\text { (beats/min) }\end{array}$ & $\begin{array}{l}\mathrm{BP} \\
(\mathrm{mm} \text { of } \mathrm{Hg})\end{array}$ & $\begin{array}{l}\text { SI } \\
\text { (seconds) }\end{array}$ \\
\hline Saline & $1 \pm 5$ & $6 \pm 4$ & $38 \pm 3$ \\
Sodium lactate & $110 \pm 10^{*}$ & $43 \pm 11^{*}$ & $13 \pm 2^{*}$ \\
Yohimbine & $112 \pm 19^{*}$ & $50 \pm 4^{*}$ & $11 \pm 1^{*}$
\end{tabular}

Rats $(n=3)$ were implanted with Alzet pumps into the DMH, inf using the GABA synthesis inhibitor L-AG. On postpump days 4,6 , and 8 they were given intravenous inf usions of either saline $(10 \mathrm{ml} / \mathrm{kg})$, sodium lactate $(10 \mathrm{ml} / \mathrm{kg}$ of $0.5 \mathrm{~N}$ solution $)$ or yohimbine $(0.4 \mathrm{mg} / 10 \mathrm{ml} / \mathrm{kg})$, and the effects on heart rate (HR), blood pressure (BP), and social interaction (SI) time were measured.

*Significantly different from saline by repeated measure ANOVA, coupled with Fisher's LSD test; $p<0.05$. Data are presented as mean \pm SEM.

Figure 8. Simplified schematic representation of the connections of the circumventricular organs and the DMH that may be involved in the lactate response. Many other connections of the DMH are not included for the sake of simplicity. It is suggested that the OVLT acts as the primary sensory site for peripheral lactate input and in turn activates the DMH to elicit a panic response. $A I I$, Angiotensin II; $B P$, blood pressure; $C G$, central gray; $D M H$, dorsomedial hypothalamus; $E A A$, excitatory amino acids; $G A B A, \gamma$-aminobutyric acid; $H R$, heart rate; $I M L$, intermediolateral column of the spinal cord; $L C$, locus ceruleus; $L H$, lateral hypothalamus; mePOA, medial preoptic area; NTS, nucleus of tractus solitarius; $O V L T$, organum vasculosum lamina terminalis; $P V N$, paraventricular nucleus of the hypothalamus; $R R$, respiratory rate; $S F O$, subfornical organ.
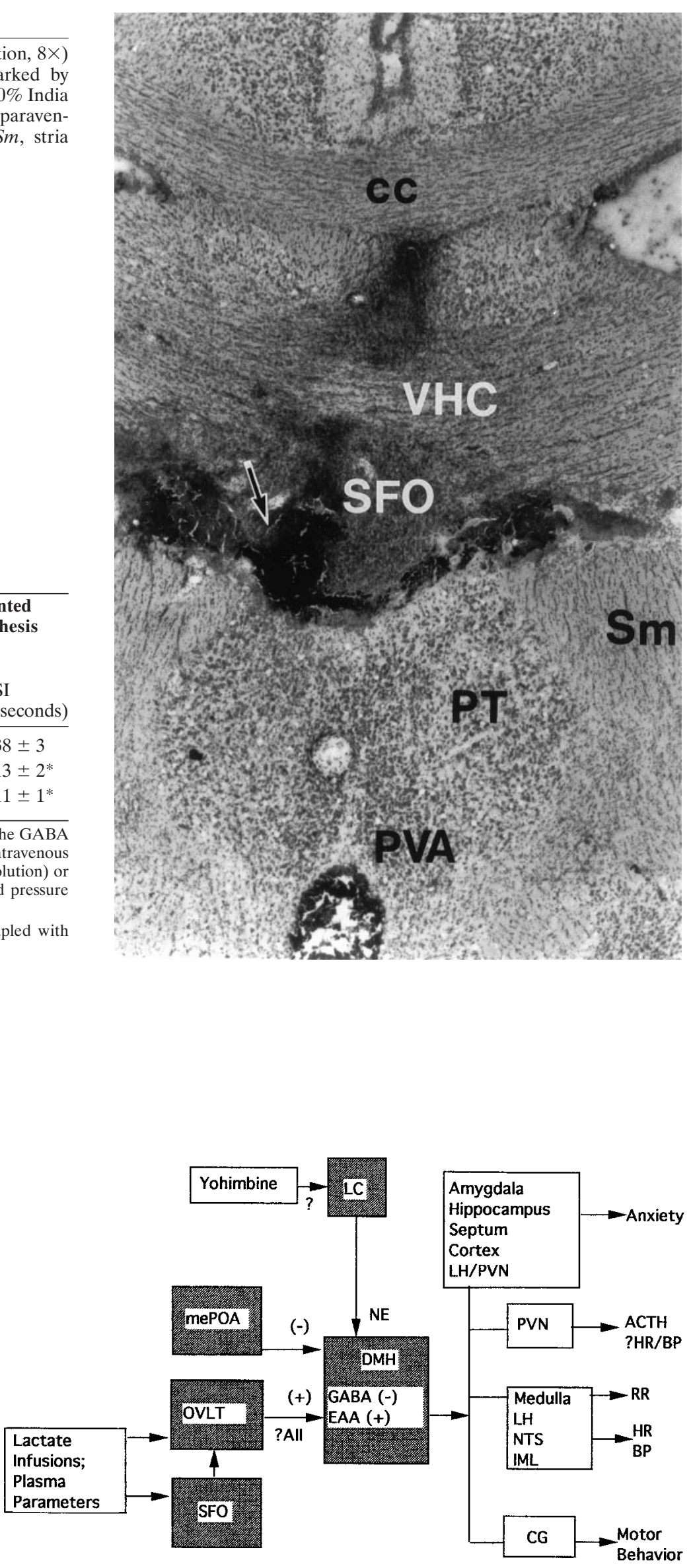


\section{REFERENCES}

Bernardis LL, Bellinger LL (1987) The dorsomedial hypothalamic nucleus revisited: an update. Brain Res Rev 12:321-381.

Bosker F, Klompmakers A, Westenberg A (1994) Extracellular 5hydroxytryptamine in median raphe nucleus of the conscious rat is decreased by nanomolar concentrations of 8-hydroxy-2-(di- $n$ propylamino)tetraline and is sensitive to tetrodotoxin. J Neurochem 63:2165-2171.

Bostwick JR, Le W-D (1991) A tyrosine hydroxylase assay in microwells using coupled nonenzymatic decarboxylation of DOPA. Anal Biochem 192:125-130.

Buggy J, Hoffman WE, Phillips MI, Fisher AE, Johnson AK (1979) Osmosensitivity of rat third ventricle and interactions with angiotensin. Am J Physiol 236:R75-R82.

Coplan JD, Sharma T, Rosenblum LA, Friedman S, Bassof TB, Barbour RL, Gorman JM (1992) Effects of sodium lactate infusion on cisternal lactate and carbon dioxide levels in nonhuman primates. Am J Psychiatry 149:1369-1373.

Corwin AL, Jorn A, Hardy M, Crawley JN (1995) The CCK-B antagonist Cl-988 increases dopamine levels in microdialysate from rat nucleus accumbens via a tetrodotoxin- and calcium-independent mechanism. J Neurochem 65:208-217.

Dager SR, Marro KI, Metzger GD, Richards TL (1992) MRS detection of whole brain lactate rise during $1 \mathrm{~m}$ sodium lactate infusion in rats. Biol Psychiatry 32:913-921.

Dager SR, Marro KI, Richards TL, Metzger GD (1994) Preliminary application of magnetic resonance spectroscopy to investigate lactateinduced panic. Am J Psychiatry 151:57-63.

Denton DA, McKinley MJ, Weisinger RS (1996) Hypothalamic integration of body fluid regulation. Proc Natl Acad Sci USA 93:7397-7404.

DiMicco JA, Abshire VM (1987) Evidence for GABAergic inhibition of a hypothalamic sympathoexcitatory mechanism in anesthetized rats. Brain Res 402:1-10.

DiMicco JA, Soltis RP, Anderson JJ, Wible Jr JH (1992) Hypothalamic mechanisms and the cardiovascular response to stress. In: Central neural mechanisms in cardiovascular regulation, Vol 2 (Kunos G, Ciriello J, eds), pp 52-79. Boston: Birkhauser.

DiScala G, Schmitt P, Karli P (1984) Flight induced by infusion of bicuculline methiodide into periventricular structures. Brain Res 309:199-208.

File SE (1980) The use of social interaction as a method for detecting anxiolytic activity of chlordiazepoxide-like drugs. J Neurosci Methods 2:219-238.

Johnson AK, Gross PM (1993) Sensory circumventricular organs and brain homeostatic pathways. FASEB J 7:678-686.

Keim SR, Shekhar A (1996) Effects of GABA Aeceptor blockade in the dorsomedial hypothalamic nucleus on corticotrophin (ACTH) and corticosterone secretion in male rats. Brain Res 739:46-51.

Kovacs KJ, Sawchenko PE (1993) Mediation of osmoregulatory influences on neuroendocrine corticotrophin-releasing factor expression by the ventral lamina terminalis. Proc Natl Acad Sci USA 90:7681-7685.

LeDoux JE, Iwata J, Cichetti P, Reis DJ (1988) Different projections of the central amygdaloid nucleus mediate autonomic and behavioral correlates of conditioned fear. J Neurosci 8:2517-2529.

Liebowitz MR, Gorman JM, Fyer A, Dillon D, Levitt M, Klein DF (1986) Possible mechanisms for lactate's induction of panic. Am J Psychiatry 143:495-502.

Orlowski M, Reingold DF, Stanley ME (1977) D- and L-stereoisomers of allylglycine: convulsive action and inhibition of brain L-glutamate decarboxylase. J Neurochem 28:349-353.

Paxinos G, Watson C (1986) The rat brain in stereotaxic coordinates, 2nd Ed. New York: Academic.

Pitts FN, McClure JN (1967) Lactate metabolism in anxiety neurosis. N Engl J Med 227:1329-1336.
Price LH, Goddard AW, Barr LC, Goodman WK (1995) Pharmacological challenges in anxiety disorders. In: Psychopharmacology: the fourth generation of progression (Bloom FE, Kupfer DJ, eds), pp 1311-1323. New York: Raven.

Reiman EM, Raichle ME, Butler FK, Herscovitch P, Robins E (1984) A focal brain abnormality in panic disorder, a severe form of anxiety. Nature 310:683-685.

Richard D, Bourque CW (1992) Synaptic activation of rat supraoptic neurons by osmotic stimulation of the organum vasculosum lamina terminalis. Neuroendocrinology 55:609-611.

Sanders SK, Shekhar A (1991) Blockade of GABA A receptors in the anterior basolateral amygdala of rats elicits increases in heart rate and blood pressure. Brain Res 576:101-110.

Sanders SK, Shekhar A (1995) GABA receptors in the basolateral amygdala of rats regulate "anxiety." Pharmacol Biochem Behav 52:701-706.

Sanders SK, Morzorati SL, Shekhar A (1995) Priming of physiological and anxiety responses by repeated subthreshold GABA blockade in the rat amygdala. Brain Res 699:250-259.

Saper CB, Loewy AD, Swanson LW, Cowan WM (1976) Direct hypothalamo-autonomic connections. Brain Res 117:305-312.

Saper CB, Levisohn D (1983) Afferent connections of the median preoptic nucleus of the rat: anatomical evidence for a cardiovascular integrative mechanism in the anteroventral third ventricular (AV3V) region. Brain Res 230:21-31.

Shekhar A (1993) GABA blockade in the region of the dorsomedial hypothalamus regulates "anxiety" in rats in the elevated plus-maze. I. Behavioral measures. Brain Res 627:9-16.

Shekhar A (1994) Effects of chronic treatment with imipramine and clonazepam in an animal model of panic disorder. Biol Psychiatry $36: 748-758$

Shekhar A, DiMicco JA (1987) Defense reaction elicited by injection of GABA antagonists and synthesis inhibitors into the posterior hypothalamus in rats. Neuropharmacology 26:407-417.

Shekhar A, Katner JS (1995) GABA $_{\mathrm{A}}$ receptors in the dorsomedial hypothalamus of rats regulate anxiety in the social interaction test. Pharmacol Biochem Behav 50:253-258.

Shekhar A, Hingtgen JN, DiMicco JA (1987) Selective enhancement of shock avoidance responding elicited by GABA blockade in the posterior hypothalamus of rats. Brain Res 420:118-128.

Shekhar A, Hingtgen JN, DiMicco JA (1990) GABA receptors in the posterior hypothalamus regulate experimental anxiety in rats. Brain Res 512:81-88.

Shekhar A, Keim SR, Simon JR, McBride WJ (1996) Physiological arousal elicited by sodium lactate infusion in rats with dorsomedial hypothalamic GABA dysfunction. Pharmacol Biochem Behav 55:249-256.

Swanson LW (1987) The hypothalamus. In: Handbook of chemical neuroanatomy, Vol 5 (Bjorklund A, Hokfelt T, Swanson LW, eds), pp 1-104. Amsterdam: Elsevier.

Ter Horst GJ, Luiten PGM (1986) Projections of the dorsomedial hypothalamic nucleus of the rat. Brain Res Bull 16:231-248.

Thrasher TN, Keil LC (1987) Regulation of drinking and vasopressin secretion: role of the organum vasculosum lamina terminalis. Am J Physiol 253:R108-R120.

Watson RE, Troiano R, Poulakos J, Weiner S, Siegel A (1982) A ${ }^{14}$ C2-deoxyglucose analysis of the neural pathways of the limbic forebrain in the rat. II. The hypothalamus. Brain Res Bull 8:459-476.

Wible Jr JH, Luft FC, DiMicco JA (1989) Hypothalamic GABA suppresses sympathetic outflow to the cardiovascular system. Hypertension 14:623-628. 